Document downloaded from:

http://hdl.handle.net/10251/101797

This paper must be cited as:

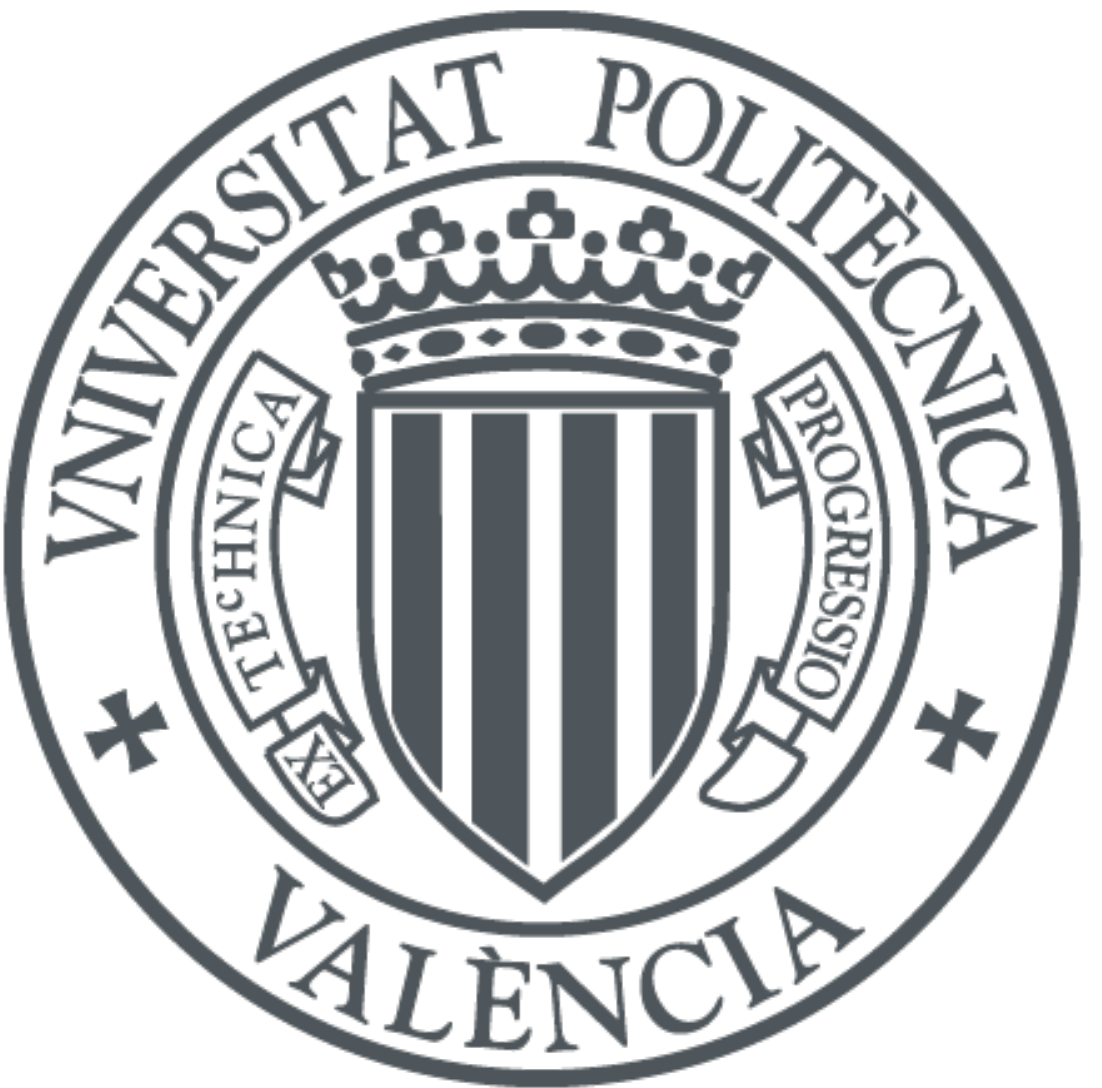

The final publication is available at

http://doi.org/10.1080/09670874.2016.1209253

Copyright Taylor \& Francis

Additional Information 


\section{Influence of pheromone emission on the attraction of California red scale males in citrus orchards}

Sandra Vacas, Jaime Primo \& Vicente Navarro-Llopis

Centro de Ecología Química Agrícola - Instituto Agroforestal del Mediterráneo

(CEQA-IAM). Universitat Politècnica de València, Valencia, Spain

Centro de Ecología Química Agrícola - Instituto Agroforestal del Mediterráneo

(CEQA-IAM). Universitat Politècnica de València. Edificio 6C-5 $5^{\mathrm{a}}$ planta, Camino de Vera s/n, 46022, Valencia, Spain. Correspondence to S. Vacas (sanvagon@ ceqa.upv.es) 


\title{
Influence of pheromone emission on the attraction of California red scale males in citrus orchards
}

\author{
Attraction of California red scale males, Aonidiella aurantii (Maskell), to \\ different release rates of the sex pheromone compound 3-methyl-6-isopropenyl- \\ 9-decen-1-yl acetate was evaluated in field trials. This study was aimed to study \\ pheromone emission-response correlations and the existence of an optimum \\ release rate that maximizes trapping efficacy. Release profiles of the pheromone \\ dispensers deployed were determined by gas chromatography to estimate the \\ various emission rates tested. The results reveal that the mean number of $A$. \\ aurantii males caught correlates with the daily pheromone release rates by means \\ of a quadratic model. The obtained model indicates the existence of a relative \\ maximum of the captures corresponding to an optimum release rate of ca. 300 \\ $\mu \mathrm{g} /$ day. Higher emission rates (up to $1 \mathrm{~g} /$ day) resulted in lower captures. \\ Implications for the mating disruption technique are discussed.
}

Keywords: Aonidiella aurantii; Diaspididae; mating disruption; mesoporous dispensers; monitoring; release rate

\section{Introduction}

The production of the sex pheromone in the California Red Scale (CRS), Aonidiella aurantii Maskell (Homoptera: Diaspididae), was described by Tashiro and Chambers (1967). They reported that a pheromone which attracts males and elicits copulatory behavior is present in virgin mature CRS females, but pheromonal compounds were identified 10 years later (Roelofs et al. 1977, 1978). CRS males were only responsive in laboratory tests to particular fractions from female airborne collections that contained 3methyl-6-isopropenyl-9-decen-1-yl acetate (I) and (Z)-3-methyl-6-isopropenyl-3,9decadien-1-yl acetate (II) (Roelofs et al. 1978). All the possible geometrical and optical isomers of the two compounds were synthetized and tested by Gieselmann et al. (1980), who found that only one isomer of each compound was significantly active: (3S,6R)-I 
and (3Z-6R)-II, and that the presence of other isomers in the mixture had no effect on trap catches. These findings led to the development of new CRS control methods based on pheromones, such as population monitoring (Gardner et al. 1983; Moreno \& Kennett 1985; Samways1988; Grout \& Richards 1991a) and mating disruption (MD) (Vacas et al. 2009a, 2010, 2015).

Pheromone monitoring systems offer great potential as a survey tool to detect small populations that often escape visual inspection, and play a key role in timing insecticide applications and parasitoid releases (Moreno \& Kennet 1985). Shaw et al. (1971) highlighted the poor reliability of visual inspections to detect CRS infestations given that pheromone traps revealed the presence of $A$. aurantii in a supposed pest-free area. This motivated research into the use of sex pheromone for monitoring purposes; first, using virgin female-baited traps (Moreno et al. 1973); second, with synthetic pheromone (Kennett \& Hoffmann 1985; Grout et al. 1989; Grout \& Richards 1991a). Pheromone lures made with rubber septa have been used widely in CRS monitoring programs, but release profiles have never been reported and the actual pheromone release rate is not known. A key factor for improvement of monitoring and pheromonebased control methods is knowledge of optimum emission rates because release rates strongly affect the attractiveness of the lure and the efficacy of the technique (Zhang \& Amalin 2005). Although previous research, mainly with lepidopteran species, has shown that trap capture may fluctuate with various pheromone emission rates (Jacobson \& Beroza 1964; Anshelevich et al. 1994; Knutson et al. 1998; Vacas et al. 2009b; Vacas et al. 2013), very little is known about the response of insects in the family Diaspididae (Moreno et al. 1972; Rice \& Hoyt 1980; McLaughlin 1990).

This study aimed to examine dose-response correlations and the existence of an optimum emission rate that maximizes the attractant activity of the A. aurantii sex 
pheromone in citrus orchards. For this purpose, several levels of pheromone load with different release rates of the commonly employed pheromone compound, 3-methyl-6isopropenyl-9-decen-1-yl acetate, were compared in traps using mesoporous pheromone dispensers (based on molecular sieves). The relationship of pheromone dose and capture of male CRS was evaluated in two field trials carried out in 2009 and 2012.

\section{Materials and methods}

\subsection{Pheromone dispensers and traps}

Cylindrical mesoporous tablets and rubber septa were employed for these trials to provide different emission rates. Mesoporous dispensers were formulated on the matrix sepiolite (natural clay mineral with a high adsorptivity for organic molecules), following the inorganic molecular sieves technology developed by Corma et al. (1999, 2000). Sepiolite is impregnated with the corresponding amount of pheromone and different additives to give consistency and protect the dispenser against humidity. The technology of mesoporous dispensers has been used as part of the Adress System commercialized by Syngenta (Madrid, Spain) against Ceratitis capitata (Wiedemann) (Navarro-Llopis et al. 2007) or more recently, for mating disruption dispensers against CRS (Vacas et al. 2009a, 2010). The manufacturing process has since been licensed to Ecologia y Protección Agrícola S.L. (Valencia, Spain) who manufactured the dispensers for this study. Two mesoporous dispensers loaded with $1 \mathrm{mg}$ (M1) and $10 \mathrm{mg}$ (M10) of the CRS sex pheromone were developed for the 2009 trial. Dispenser M1 was $9 \mathrm{~mm}$ in diameter and $3.5 \mathrm{~mm}$ high, whereas M10 was $13 \mathrm{~mm}$ in diameter and $7.5 \mathrm{~mm}$ high. The 2012 trial also employed two mesoporous dispensers, loaded with $5 \mathrm{mg}$ (M5; $13 \mathrm{~mm}$ in diameter and $3.5 \mathrm{~mm}$ high) and $65 \mathrm{mg}(\mathrm{MD} ; 9 \mathrm{~mm}$ in diameter and $10 \mathrm{~mm}$ high) of 
pheromone. These MD dispensers correspond to those reported in Vacas et al. (2010) developed for CRS mating disruption treatments. Red rubber septa dispensers supplied by Ecología y Protección Agrícola SL (Valencia, Spain), containing ca. 3 mg of pheromone were also used in the 2012 trial. All dispensers (mesoporous and rubber septa) contained the diastereomeric mixture $(3 \mathrm{~S}, 6 \mathrm{R}$ and $3 \mathrm{~S}, 6 \mathrm{~S})$ of 3-methyl-6isopropenyl-9-decen-1-yl acetate with $75 \%$ chemical purity; the remaining $25 \%$ belonged to the by-product 3-methyl-6-isopropylidene-9-decen-1-yl acetate, showing no pheromonal activity.

White sticky boards $(95 \times 150$ mm; Ecología y Protección Agrícola SL, Valencia, Spain) were used to capture male CRS in field trials. Each trap was baited with the corresponding pheromone dispensers, as described below.

\subsection{Experiment 1: 2009 Trial}

The field trial was conducted in a 3 ha mandarin (Citrus reticulata Blanco; var. Ortanique) orchard located in Denia (Alicante, Spain; UTM: X243500 Y4303900) under Mediterranean climate conditions. Trees were 20 years old (aprox. $2.5 \mathrm{~m}$ in height, $2 \mathrm{~m}$ average crown spread) and were spaced $6 \mathrm{~m} \times 4 \mathrm{~m}$. This field trial included four replicates (ca. 0.2-ha blocks) to evaluate the capture efficacy of four different pheromone emission rates. For this purpose, four traps were placed in a row inside each block following a randomized complete block design. Therefore, each block contained a trap baited with: (A2) two M1 dispenser, (A5) five M1 dispensers, (A10) one M10 dispenser, and (A30) three M10 dispensers. Traps were hung in the canopy of mandarin trees at an approximate height of $1.5 \mathrm{~m}$ spaced at least $25 \mathrm{~m}$ apart, with each block at least 50 m apart. Traps were placed in the field on 2 July 2009 and their position was 
rotated within each block weekly. The number of CRS males caught was counted weekly, for 9 weeks.

\subsection{Experiment 2: 2012 Trial}

This field trial was conducted in the same aforementioned orchard and included four replicates (ca. 0.2-ha blocks) to evaluate the capture efficacy of five different pheromone emission rates and also a trap without pheromone lure. For this purpose, six traps were placed in a row inside each block (following a randomized complete block design). Therefore, each block contained a trap baited with: RUB (one rubber septum), B5 (one M5 dispenser), B25 (five M5 dispensers), MD (one MD dispenser), 2MD (two MD dispensers), and an unbaited trap (0). Traps were hung in the canopy on 27 June 2012 and were spaced at least $25 \mathrm{~m}$ apart, with each block at least $50 \mathrm{~m}$ apart. Position of traps was rotated within each block weekly and the number of CRS males caught was counted weekly, for 6 weeks.

\subsection{Pheromone release profiles}

Simultaneously to the field trials, additional dispensers of each type were aged in a nearby area, located at least $500 \mathrm{~m}$ away from the trial orchard. Three dispensers of each type were taken from the field every 1-2 weeks and their residual pheromone content was extracted to study their release profiles. Dispensers were aged during the corresponding study periods, for 69 days in the 2009 trial and at least 42 days in the 2012 trial. These dispensers were extracted by solvent extraction at $40^{\circ} \mathrm{C}$ for $2 \mathrm{~h}$, with magnetic agitation and methanol + dichloromethane $(3: 2, \mathrm{v} / \mathrm{v})$ as solvent (Vacas et al. 2010). 
The resulting extracts were then analysed by gas chromatography with a flame ionization detector (GC/FID) using a Clarus®500 gas chromatograph (PerkinElmer Inc., Wellesley, USA) and the residual pheromone content ( $\mu \mathrm{g}$ or mg of the aforementioned diastereomeric mixture) was quantified using $n$-dodecane as the internal standard. All the analysis were performed on a ZB-5 $(30 \mathrm{~m} \times 0.25 \mathrm{~mm} \times 0.25 \mathrm{~mm})$ column (Phenomenex Inc., Torrance, CA), held at $160^{\circ} \mathrm{C}$ for $5 \mathrm{~min}$ and then programmed at $2^{\circ} \mathrm{C} / \mathrm{min}$ up to $180^{\circ} \mathrm{C}$, where it was held for $1 \mathrm{~min}$, and then programmed at $45^{\circ} \mathrm{C} / \mathrm{min}$ up to $250^{\circ} \mathrm{C}$. The carrier gas was helium at $1.2 \mathrm{~mL} / \mathrm{min}$. The amounts of pheromone and the GC responses were connected by fitting a linear regression model, $y=\mathrm{a}+\mathrm{b} x$, where $y$ is the response ratio [pheromone/ $n$-dodecane] and $x$ is the amount of pheromone remaining in the dispensers.

\subsection{Statistical analysis}

The quantified residual pheromone loads ( $\mu \mathrm{g}$ or $\mathrm{mg}$ ) for each dispenser were fitted by simple or multiple regression with the independent variable time (number of ageing days). The first derivative of the resulting equations provided an estimation of the emission rates.

The number of CRS males captured per trap per day (MTD: males per trap per day) were log-transformed to normalize the distributions and to homogenize variance prior to applying the analysis of variance. A multifactor-ANOVA (Fisher least significant difference [LSD] test at $P<0.05$ ) was performed to study the differences between trap catches according to three factors: week, block and emission level. After checking that the emission level had a significant effect on captures, we wanted to study the correlation between catch data and the pheromone emission rates tested and determine the existence of a relative maximum of captures. For this purpose, a two-way 
ANOVA was performed with capture data only with factors week and block. In this way, data variance due to the two factors week and block was removed and the residuals of this ANOVA still provided evidence for variance owing to the emission level factor. Thus, these residuals were employed to perform the multiple regression analysis to obtain the correlation trap captures-emission and explain the effect of pheromone emission on CRS male trapping (Vacas et al. 2009b). Statistical analyses were performed using the Statgraphics Centurion XVI package (StatPoint Technologies, Warrenton, VA, USA).

\section{Results}

\subsection{Pheromone release profiles}

After quantifying the mean residual pheromone loads (ph), the release profile of dispenser M1 was fitted to the linear model given by equation $1\left(R^{2}=0.95\right.$; Figure $\left.1 \mathrm{a}\right)$ : $\mathrm{ph}(\mu \mathrm{g})_{\mathrm{M} 1}=594.59-4.16 \times$ days

Multiple linear regression demonstrated that the quadratic effect was not statistically significant $(P=0.44)$ and the linear model indicates that pheromone load of M1 decreased at a constant rate throughout the study period. Thus, the emission rate was given by the slope of equation 1 and equaled $4.16 \mu \mathrm{g} /$ day. Likewise, dispensers M5 and M10 also presented decreasing linear profiles (Figure $2 \mathrm{a}$ and $1 \mathrm{~b}$, respectively). The emission of dispenser M5 was constant and equaled $57.11 \mu \mathrm{g} /$ day, according the linear model $\left(\mathrm{R}^{2}=0.94\right.$, significance of quadratic term: $\left.P=0.21\right)$ given by equation 2 and fitted to residual pheromone values shown in Figure $2 \mathrm{a}$.

$\mathrm{ph}(\mu \mathrm{g})_{\mathrm{M} 5}=5839.14-57.11 \times$ days 
Dispenser M10 released the CRS sex-pheromone at a constant rate of 38.35

$\mu \mathrm{g} /$ day, given by the model of equation 3 depicted in Figure $1 \mathrm{~b}\left(\mathrm{R}^{2}=0.91\right.$, significance of quadratic term: $P=0.06)$.

$\mathrm{ph}(\mathrm{mg})_{\mathrm{M} 10}=7.41712-0.03835 \times$ days

However, the MD mesoporous dispensers displayed a different performance, as shown in Figure $2 \mathrm{~b}$. The residual pheromone loads fitted the exponential model $\left(\mathrm{R}^{2}=\right.$ 0.91) given by equation 4 , which indicates that pheromone emission was not constant and decreased over time.

$\mathrm{ph}(\mathrm{mg})_{\mathrm{MD}}=63.66 \times \mathrm{e}-0.008 \cdot$ days

Thus, the first derivative of the fitted model (equation 4) allowed the estimation of the MD dispensers for each trapping period (by applying days $=\mathrm{i}$; $\mathrm{i}$ being the midpoint of the trapping period; i.e. days $=10.5$, the midpoint of the 7-14 days period). All the estimated emission values are indicated in Table 2, and were assumed constant throughout each time interval.

Finally, the rubber septa dispensers released CRS sex-pheromone at a constant rate of $29.75 \mu \mathrm{g} /$ day, calculated according to the linear model $\left(\mathrm{R}^{2}=0.96\right)$ given by equation 5 (non-significant quadratic effect, $P=0.59$ ) in Figure 2c.

$\mathrm{ph}(\mu \mathrm{g})_{\mathrm{RUB}}=2605.4-29.75 \times$ days

\subsection{Experiment 1: 2009 Trial}

The mean male captures per trap per day $(\mathrm{MTD} \pm \mathrm{SE})$ obtained with each type of baited trap arranged in the 2009 trial are depicted in Figure 3. After data normalization, the multifactor-ANOVA showed that factors week and block had a significant effect on trap catches (week: $F=61.7 ; \mathrm{df}=8,121 ; P<0.001$; block: $F=5.93 ; \mathrm{df}=3,121 ; P<0.001$ ), due to the natural population dynamics and the clumped distribution of this pest. The 
emission factor had no full significant effect on trap catches $(F=2.05 ; \mathrm{df}=3,121 ; P=$ 0.11); only the mean MTD caught in traps A2 was significantly lower than that obtained in traps A30 (Figure 3).

According the pheromone release profiles calculated above for each type of dispenser, the emission factor can be considered a quantitative variable according to the release rates estimated for the traps baited for this trial (Table 1). The residuals of the two-way ANOVA performed with factors week and block analysis contained the data variability due to the emission factor; thus, these residuals were employed in a subsequent multiple regression analysis with the calculated release rates. The results indicate that the quadratic effect was not statistically significant $(P=0.83$, Figure 4$)$, suggesting the absence of a relative maximum of catches corresponding to an optimum emission level within the emission range studied in this trial $(8.32-115.05 \mu \mathrm{g} /$ day $)$.

\subsection{Experiment 2: 2012 Trial}

The second trial included higher pheromone release rates in an attempt to either confirm the linearity in the captures' trend or find the optimum emission level that maximizes pheromone attraction. The MTD data obtained are provided in Figure 5, which highlights that the mean captures obtained in the traps baited with 1 or $2 \mathrm{MD}$ dispensers (MD and 2MD) did not significantly differ from the captures obtained by chance in the control traps without pheromone bait (0); on the other hand, the traps with one or five M5 dispensers (B5 and B25) recorded the largest captures (Figure 5). Following the aforementioned statistical procedure, the multifactor-ANOVA revealed that factors week and block significantly affected captures (week: $F=41.9$; $\mathrm{df}=6,120 ; P<0.001$;

block: $F=5.55 ; \mathrm{df}=3,120 ; P<0.001)$, as did the emission factor $(F=16.9 ; \mathrm{df}=5,120$; $P<0.001$ ), thus confirming the influence of pheromone emission on attraction. 
As described in the previous section, the estimated release rates (Table 1 and 2) for the traps baited for 2012 trial were employed in a subsequent multiple regression analysis with the residuals saved from the two-way ANOVA performed with factors week and block. The quadratic effect was evaluated and was significant $(P<0.001)$, which demonstrates the existence of a relative maximum of captures corresponding to an optimum emission value (Figure 6). The analysis gave the model provided by Equation 6. To obtain the emission value that maximizes pheromone attractant activity, Equation 6 was derived and equalled zero, and resulted in an optimum release rate of $299.3 \mu \mathrm{g} /$ day.

$$
\text { Residuals }=0.01229+0.00138 \times(\text { emission })-0.0000023 \times(\text { emission })^{2}
$$

\section{Discussion}

The trials reported in the present study confirm the influence of pheromone emission on CRS male attraction, obtaining a relative maximum of the captures corresponding to an optimum release rate of ca. $300 \mu \mathrm{g} / \mathrm{day}$. This influence was previously observed by Rice and Moreno (1969a) when they compared the attraction of increasing numbers of female scales within the range $0-400 \mathrm{CRS}$ females/trap. Their results indicated that about $50-100$ pheromone-producing females per trap would be sufficient to collect males. By taking into account the natural mortality of females in the field, Rice and Moreno (1969a) proposed a standardized attractant level of some 300 females/trap, which was employed in subsequent field tests (Rice \& Moreno 1969b; Shaw et al. 1971; Moreno et al. 1973). This was the starting point for monitoring formulations with synthetic pheromone. Moreno and Kennett (1985) demonstrated that rubber septum containing $120 \mu \mathrm{g}$ of 3-methyl-6-isopropenyl-9-decen-1-yl acetate (I) approximated the 
attractiveness of 200 virgin females. However, commercial rubber septa formulations have increased the pheromone load to $250 \mu \mathrm{g}$, like those employed in the above-cited MD studies, but no reported study justifies this reasoning. Generally, producers tend to increase the pheromone load of dispensers to obtain maximum efficacy and longevity but knowledge and optimization of emission rates and pheromone release profiles are essential for better pheromone use. Rubber septa dispensers are commonly characterized by highly temperature-dependent release kinetics (McDonough et al. 1989; Domínguez-Ruiz et al. 2008). For this reason, the performance of rubber septa dispensers is not always optimized, which may lead to irregular captures and can provide mistaken estimation of pest populations. The release profile of the rubber septa dispensers employed in this work was studied, to show a mean initial load of ca. $2.5 \mathrm{mg}$ and a constant emission of $29.75 \mu \mathrm{g} /$ day in the study period. The residual pheromone load after 42 days of field exposure was $47 \%$ of the initial content, which probably allows a longer lifespan than the commonly employed septa, with recommended replacement periods of 6 weeks.

According our results, the optimum pheromone release rate for attraction did not fall within the emission range tested in 2009 (8.32 - $115.05 \mu \mathrm{g} /$ day), given that statistical analysis revealed a not significant effect of the tested emission rate on CRS captures. When higher release rates were included in the subsequent trial 2012, the model obtained by the multiple regression analysis indicated an optimum release rate of ca. $300 \mu \mathrm{g} /$ day for maximum CRS attraction. Higher emission rates (up to $1 \mathrm{~g} /$ day) resulted in lower captures, which highlights the disorientation effect of males toward a pheromone source. This should relate to the release value recommended by Vacas et al. (2009a) for MD with mesoporous dispensers. In those preliminary trials, MD treatment was not effective with pheromone doses of 40-90 $\mu \mathrm{g} /$ day/dispenser, but the level of 
disruption was satisfactory with emission values ca. $250 \mu \mathrm{g} /$ day/dispenser, and with no significant differences found for the plots treated with $390 \mu \mathrm{g} /$ day/dispenser. In the present work, maximum attractant power was found with the traps releasing 300 $\mu \mathrm{g} /$ day, which disagrees with the male flight disruption observed in MD treatments with the dispensers releasing $250 \mu \mathrm{g} /$ day. This could be explained by the particular mechanisms that take part in CRS mating disruption. No information on this aspect is available, but the MD treatment described by Vacas et al. (2009a) employs a dispenser density of 1 per tree (> 400 dispensers/ha). This suggests that pheromone point sources releasing about $250 \mu \mathrm{g} / \mathrm{day}$, at the aforementioned density, would be adequate to maintain a suitable amount of pheromone in the orchard atmosphere able to disrupt male trail-following toward females (camouflage) or cause competition between point sources (females vs. dispensers), rather than producing antennae saturation and therefore, adaptation or habituation (Cardé \& Minks 1995).

In general, there is scarce information about the influence of pheromone emission on Diaspididae species. Results obtained in the present work suggest an optimum emission rate of $\sim 300 \mu \mathrm{g}$ /day for maximum CRS attraction. Besides providing valuable information on the behaviour of this specie, this data is useful for optimization of the mating disruption technique recently commercialized for CRS.

\section{Acknowledgements}

The authors want to thank Fernando Alfaro for providing trial orchards and Ecologia y Protección Agrícola SL for mating disruption dispensers and pheromone supply. We are also grateful to Helen Warburton for English editing.

\section{Funding}

The research leading to these results received funding from the Spanish Ministry of Science and Innovation (project AGL2009-10725). 


\section{Disclosure statement}

This manuscript and the authors of the manuscript are not involved in any potential conflicts of interest, including financial interests and relationships and affiliations. 


\section{References}

Anshelevich L, Kehat M, Dunkelblum E, Greenberg S. 1994. Sex pheromone traps for monitoring the European vine moth, Lobesia botrana- Effect of dispenser type, pheromone dose, field aging of dispenser, and type of trap on male captures. Phytoparasitica 22:281-290.

Cardé RT, Minks AK. 1995. Control of moth pests by mating disruption: Successes and constraints. Ann Rev Entomol. 40:559-585.

Corma A, Muñoz Pallarés J, Primo-Yúfera E. 1999. Production of semiochemical emitters having a controlled emission speed which are based on inorganic molecular sieves. World Patent WO9944420.

Corma A, Muñoz Pallarés J, Primo-Yúfera E. 2000. Emitter of semiochemical substances supported on a sepiolite, preparation process and applications. World Patent WO0002448.

Domínguez-Ruiz J, Sanchis J, Navarro-Llopis V, Primo J. 2008. A new long-life trimedlure dispenser for Mediterranean fruit fly. J Econ Entomol. 101:1325-1330.

Gardner PD, Ervin RT, Moreno DS, Baritelle JL. 1983. California Red Scale (Homoptera: Diaspididae) - cost-analysis of a pheromone monitoring program. J Econ Entomol. 76:601-604.

Gieselmann MJ, Henrick CA, Anderson RJ, Moreno DS, Roelofs WL. 1980. Responses of male California red scale to sex-pheromone isomers. J Insect Physiol. 26:179-182.

Grafton-Cardwell EE, Reagan CA. 1995. Selective use of insecticides for control of armored scale (Homoptera: Diaspididae) in San-Joaquin Valley California citrus. J Econ Entomol. 88:1717-1725. 
Grafton-Cardwell EE, Lee JE, Stewart JR, Olsen KD. 2006. Role of two insect growth regulators in integrated pest management of citrus scales. J Econ Entomol. 99:733-744.

Grout TG, Du Toit WJ, Hofmeyr JH, Richards GI. 1989. California red scale (Homoptera: Diaspididae) phenology on citrus in South Africa. J Econ Entomol. 82:793-798.

Grout TG, Richards GI. 1991a. Value of pheromone traps for predicting infestations of Red Scale, Aonidiella aurantii (Maskell) (Hom, Diaspididae), limited by natural enemy activity and insecticides used to control citrus thrips, Scirtothrips aurantii Faure (Thys, Thripidae). J Appl Entomol. 111:20-27.

Grout TG, Richards GI. 1991b. Effect of buprofezin applications at different phenological times on California red scale (Homoptera: Diaspididae). J Econ Entomol. 84:1802-1805.

Jacobson M, Beroza M. 1964. Insect Attractants. Sci Am. 211:20-27.

Kennett CE, Hoffmann RW. 1985. Seasonal development of the California red scale (Homoptera: Diaspididae) in San-Joaquin Valley citrus based on degree-day accumulation. J Econ Entomol. 78:73-79.

Knutson AE, Marvin I, Harris K, Millar JG. 1998. Effects of pheromone dose, lure age, and trap design on capture of male pecan nut casebearer (Lepidoptera: Pyralidae) in pheromone-baited traps. J Econ Entomol. 91:715-722.

McDonough LM, Brown DF, Aller WC. 1989. Insect sex pheromones. Effect of temperature on evaporation rates of acetates from rubber septa. J Chem Ecol. 15:779-790. 
McLaughlin JR. 1990. Behavioral response of male white peach scale to the sex pheromone, (R,Z)-3,9,-dimethyl-6-isopropenyl-3,9-decadien-1-ol propionate and corresponding alcohol. J Chem Ecol. 16:749-756.

Moreno DS, Carman GE, Bain NS. 1972. Extraction and bioassay of, and effect of solvents on the sex pheromone of the yellow scale. Ann Entomol Soc Am. 65:1061-1064.

Moreno D, Fargerlund J, Shaw J. 1973. California red scale: captures of males in modified pheromone traps. J Econ Entomol. 66:1333-1333.

Moreno DS, Kennett CE. 1985. Predictive year-end California red scale (Homoptera: Diaspididae) orange fruit infestations based on catches of males in the San-Joaquin Valley. J Econ Entomol. 78:1-9.

Navarro-Llopis V, Sanchis J, Primo-Millo J, Primo-Yúfera E. 2007. Chemosterilants as control agents of Ceratitis capitata (Diptera: Tephritidae) in field trials. B Entomol Res. 97:359-368.

Rice RE, Moreno DS. 1969a. Flight of male California red scale. Ann Entomol Soc Am. 63:91-96.

Rice RE, Moreno DS. 1969b. Marking and recapture of California red scale for field studies. Ann Entomol Soc Am. 62:558-560.

Rice RE, Hoyt SC. 1980. Response of San Jose scale to natural and synthetic sex pheromones. Environ Entomol. 9:190-194.

Roelofs WL, Gieselmann MJ, Cardé AM, Tashiro H, Moreno DS, Henrick CA, Anderson RJ. 1977. Sex-pheromone of California red scale, Aonidiella aurantii. Nature 267:698-699. 
Roelofs WL, Gieselmann MJ, Cardé AM, Tashiro H, Moreno DS, Henrick CA, Anderson RJ. 1978. Identification of the California red scale sex pheromone. J Chem Ecol. 4:211-224.

Samways MJ. 1988. Comparative monitoring of Red scale Aonidiella aurantii (Mask) (Hom, Diaspididae) and its Aphytis spp (Hym, Aphelinidae) parasitoids. J Appl Entomol. 105:483-489.

Shaw JG, Moreno DS, Fargerlund J. 1971. Virgin female California red scales used to detect infestations. J Econ Entomol. 64:1305-1306.

Tashiro H, Chambers DL. 1967. Reproduction in the California red scale, Aonidiella aurantii (Homoptera: Diaspididae). I. Discovery and extraction of a female sex pheromone. Ann Entomol Soc Am. 60:1166-1170.

Vacas S, Alfaro C, Navarro-Llopis V, Primo J. 2009a. The first account of the mating disruption technique for the control of California Red Scale Aonidiella aurantii Maskell (Homoptera: Diaspididae) using new biodegradable dispensers. B Entomol Res. 99:415-423.

Vacas S, Alfaro C, Navarro-Llopis V, Zarzo M, Primo J. 2009b. Study on the optimum pheromone release rate for attraction of Chilo suppressalis (Lepidoptera: Pyralidae). J Econ Entomol. 102:1094-1100.

Vacas S, Alfaro C, Navarro-Llopis V, Primo J. 2010. Mating disruption of California red scale, Aonidiella aurantii Maskell (Homoptera: Diaspididae), using biodegradable mesoporous pheromone dispensers. Pest Manag Sci. 66:745-751.

Vacas S, Miñarro M, Bosch MD, Primo J, Navarro-Llopis V. 2013. Studies on the codling moth (Lepidoptera: Tortricidae) response to different codlemone release rates. Environ Entomol. 42:1383-1389. 
Vacas S, Alfaro C, Primo J, Navarro-Llopis V. 2015. Deployment of mating disruption dispensers before and after first seasonal male flights for the control of Aonidiella aurantii in citrus. J Pest Sci. 88:321-329.

Zhang AJ, Amalin D. 2005. Sex pheromone of the female pink hibiscus mealybug, Maconellicoccus hirsutus (Green) (Homoptera : Pseudococcidae): biological activity evaluation. Environ Entomol. 34:264-270. 
Table 1. Estimated pheromone release rates for traps baited with M1, M10 and M5 dispensers in trials 2009 and 2012.

\begin{tabular}{|c|c|c|c|c|}
\hline Trial & Trap & Bait $^{1}$ & $\begin{array}{c}\text { release } \\
\text { rate } \\
(\mu \mathrm{g} / \mathrm{day})\end{array}$ & $\begin{array}{l}\text { Procedure of } \\
\text { estimation }^{2}\end{array}$ \\
\hline \multirow{4}{*}{2009} & A2 & $2 \times \mathrm{M} 1$ & 8.32 & $2 \times \mathrm{d}($ eq. 1$) / \mathrm{dt}$ \\
\hline & A5 & $5 \times \mathrm{M} 1$ & 20.8 & $5 \times \mathrm{d}($ eq. 1$) / \mathrm{dt}$ \\
\hline & A 10 & $1 \times \mathrm{M} 10$ & 38.35 & $1 \times \mathrm{d}($ eq. 3$) / \mathrm{dt}$ \\
\hline & A 30 & $3 \times \mathrm{M} 10$ & 115.05 & $3 \times \mathrm{d}($ eq. 3$) / \mathrm{dt}$ \\
\hline \multirow{6}{*}{2012} & 0 & no bait & 0 & - \\
\hline & RUB & $\begin{array}{c}1 \times \text { rubber } \\
\text { septum }\end{array}$ & 29.75 & $1 \times \mathrm{d}($ eq. 5$) / \mathrm{dt}$ \\
\hline & B5 & $1 \times$ M5 & 57.11 & $1 \times \mathrm{d}($ eq. 2$) / \mathrm{dt}$ \\
\hline & B25 & $5 \times \mathrm{M} 5$ & 285.55 & $5 \times \mathrm{d}($ eq. 2$) / \mathrm{dt}$ \\
\hline & MD & $1 \times \mathrm{MD}$ & \multicolumn{2}{|c|}{ see table 2} \\
\hline & $2 \mathrm{MD}$ & $2 \times \mathrm{MD}$ & \multicolumn{2}{|c|}{ see table 2} \\
\hline
\end{tabular}

${ }^{1}$ Number and type of dispensers contained in the trap

${ }^{2}$ Procedure used to calculate release rates from traps: derivative of the equation indicated within parentheses, taking into account the number of dispensers contained in the trap. 
Table 2. Estimated pheromone emission rates for traps baited with MD dispensers in trial 2012: MD (1 dispenser) and 2MD (2 dispensers).

\begin{tabular}{|c|c|c|c|c|}
\hline $\begin{array}{c}\text { Day } \\
\text { period }\end{array}$ & Date $^{1}$ & Trap & $\begin{array}{c}\text { Release } \\
\text { rate } \\
(\mu \mathrm{g} / \mathrm{day})\end{array}$ & $\begin{array}{l}\text { Procedure of } \\
\text { Estimation }^{2}\end{array}$ \\
\hline \multirow[t]{2}{*}{$0-7$} & \multirow[t]{2}{*}{ 4-Jul-2012 } & MD & 495.2 & $\mathrm{~d}($ eq. 4$) / \mathrm{dt}_{\mathrm{t}=3.5}$ \\
\hline & & $2 \mathrm{MD}$ & 990.5 & $2 \times \mathrm{d}($ eq. 4$) / \mathrm{dt}_{\mathrm{t}=3.5}$ \\
\hline \multirow[t]{2}{*}{$7-14$} & \multirow[t]{2}{*}{ 11-Jul-2012 } & MD & 468.3 & $\mathrm{~d}($ eq. 4$) / \mathrm{dt}_{\mathrm{t}=10.5}$ \\
\hline & & $2 \mathrm{MD}$ & 936.5 & $2 \times \mathrm{d}($ eq. 4$) / \mathrm{dt}_{\mathrm{t}=10.5}$ \\
\hline \multirow[t]{2}{*}{$14-21$} & \multirow[t]{2}{*}{ 18-Jul-2012 } & $\mathrm{MD}$ & 442.8 & $\mathrm{~d}($ eq. 4$) / \mathrm{dt}_{\mathrm{t}=17.5}$ \\
\hline & & $2 \mathrm{MD}$ & 885.5 & $2 \times \mathrm{d}($ eq. 4$) / \mathrm{dt}_{\mathrm{t}=17.5}$ \\
\hline \multirow[t]{2}{*}{$21-28$} & \multirow[t]{2}{*}{ 25-Jul-2012 } & MD & 418.6 & $\mathrm{~d}($ eq. 4$) / \mathrm{dt}_{\mathrm{t}=24.5}$ \\
\hline & & $2 \mathrm{MD}$ & 837.3 & $2 \times \cdot d($ eq. 4$) / \mathrm{dt}_{\mathrm{t}=24.5}$ \\
\hline \multirow[t]{2}{*}{$28-35$} & \multirow[t]{2}{*}{ 1-Aug-2012 } & MD & 395.8 & $\mathrm{~d}($ eq. 4$) / \mathrm{dt}_{\mathrm{t}=31.5}$ \\
\hline & & $2 \mathrm{MD}$ & 791.7 & $2 \times \mathrm{d}($ eq. 4$) / \mathrm{dt}_{\mathrm{t}=31.5}$ \\
\hline \multirow[t]{2}{*}{$35-42$} & \multirow[t]{2}{*}{ 8-Aug-2012 } & MD & 374.3 & $\mathrm{~d}($ eq. 4$) / \mathrm{dt}_{\mathrm{t}=38.5}$ \\
\hline & & $2 \mathrm{MD}$ & 748.6 & $2 \times \mathrm{d}($ eq. .4$) / \mathrm{dt}_{\mathrm{t}=38.5}$ \\
\hline
\end{tabular}

${ }^{1}$ Date at which traps were inspected for counting.

${ }^{2}$ Procedure used to calculate mean release rates: applying $t=\mathrm{i}$ (i being midpoint of the period) to the respective derived equation indicated within parentheses. 


\section{Figure captions}

Figure 1. Pheromone release profiles of the dispensers employed in the 2009 Trial: (a) M1 dispenser, and (b) M10 dispenser, as residual pheromone load ( $\mu \mathrm{g}$ or mg) contained in the dispensers vs. the time of field exposure (days). Release kinetics fitted to linear models given by the respective equations.

Figure 2. Pheromone release profiles of the dispensers employed in the 2012 Trial: (a) M5 dispenser, (b) mating disruption (MD) dispenser, and (c) rubber septa, as residual pheromone load ( $\mu \mathrm{g}$ or $\mathrm{mg}$ ) contained in the dispensers vs. the time of field exposure (days). Release kinetics fitted to models given by the respective equations.

Figure 3. Mean $( \pm$ SE) number of CRS males captured per trap and day (MTD) for each of the four types of baited trap tested in Experiment 1: 2009 trial. Bars labelled with different letters were significantly different (LSD test at $\mathrm{P}<0.05)$.

Figure 4. Mean $( \pm$ SE) residuals from the ANOVA performed with factors week and block in the Experiment 1: 2009 trial. Multiple regression analysis performed to correlate the dependent variable residuals with the factor emission did not found evidences for an optimum emission rate in the range $8.32-115.05 \mu \mathrm{g} / \mathrm{day}$.

Figure 5. Mean $( \pm \mathrm{SE})$ number of CRS males captured per trap and day (MTD) for each of the five types of baited trap tested in the Experiment 2: 2012 trial. A trap without pheromone lure was also included (0). Bars labelled with different letters were significantly different (LSD test at $\mathrm{P}<0.05)$.

Figure 6. Mean $( \pm \mathrm{SE})$ residuals from the ANOVA performed with factors week and block vs. sqrt-emission rates studied in the 2012 Trial. Multiple regression analysis found a significant effect of factor emission, which demonstrates the existence of a relative maximum of captures corresponding to an optimum emission value. 